\title{
Studies on the Growth and Reproduction of Waterhyacinth, Eichhornia crassipes (Mart.) Solms
}

1. Effect of Nutrients on the Growth and Reproduction

Yoko OKI, Misako Ito, and Kunikazu UeKI

Faculty of Agriculture, Kyoto University, Kyoto 606

\section{Summary}

The purpose of this fundamental experiments was to determine the effect of nutrients on the growth and reproduction of waterhyacinth. The results obtained were as follows:

1) Plants grown in each solution with $\mathrm{N}, \mathrm{P}$ or $\mathrm{Ca}$ deficiency depressed the growth and reproduction. Chemical analysis revealed that phosphorus content of the aerial portions was low in all above mentioned treatments.

2) As the ammonium $\mathrm{N}$ levels was increased from 0 to $160 \mathrm{ppm}$ in culture solution, the growth of adult plant increased. While in young plant the maximum growth occured in the $40 \mathrm{ppm}$ ammonium $\mathrm{N}$ solution. Also they produced a greater number of new plants in the $40 \mathrm{ppm}$ and the growth of new plants was maximum in this treatment. These results indicated that the optimum growth differed from the optimum reproduction in the nitrogen requirements.

3) The effect of various levels of phosphorus and calcium on the growth and reproduction was investigated. Plants grew well in water with a phosphate level over than $20 \mathrm{ppm}$. As the phosphate content of the water was increased from 0 to $40 \mathrm{ppm}$, phosphorus content of the aerial portions increased. While in calcium oxide, the minimum threshold concentration that showed normal growth was $5 \mathrm{ppm}$. Even when the content of the water was increased, calcium content of the plant was not increased except the treatment of $80 \mathrm{ppm}$.

\section{ホテイアオイ (Eichhornia crassipes (Mart.) Solms) の 生育及び繁殖に関する研究}

\section{第 2 報＼cjkstart水中の窒素形態の差異が生育ならびに繁殖に及ぼす影響*}

\author{
京都大学農学部 沖 陽子・伊藤操子・植木邦和
}

前報 ${ }^{5)}$ において，ホテイアオイの生育，繁殖に著しい 影響を与える主要要素は, 窒素, 燐およびカルシウムで あることを明らかにしたが，特に窒素に関しては，水の 富栄養化の推進力であり, かつ, 本草の吸収量が大きい ことが知られているので, 窒素に対する反応を適確に把 握することの必要を指摘した。ところで, 前報の実験で は，窒素についてアンモニア態のみを扱ってきたが，実 際のホテイアオイの発生水域では, 硝酸態の影響も無視
できない。一般に窒素源としてのアンモニア態窒素と硝 酸態窒素の優劣については，古くから種々の作物につい て研究が行われているが，両形態に対する反応は，同一 種においても，植物の内的条件及び外的条件により影響 されやすいと報告されている7。 ホテイアオイの場合, 大垣 $(1974)^{4)}$ は, 硝酸態窒素を好むと報告しているが, 本草が硝酸態に対して, どのような生育を呈するか, ア ンモニア態及びアンモニア態と硝酸態との混合の場合と

* 日本雑草学会第 15 回講演会（1976 年 4 月）において発表 
比較して，どのような差を生じるか検討を加えてみた。 また，両形態が生育と繁殖及び植物体内の無機成分含量 に及ぼす影響を $\mathrm{pH}$ の高低との関係で調べた。

\section{1. 実験材料及び方法}

供試個体は葉数 $5 \sim 6$ 葉, 生体重 $40 \mathrm{~g}$ 前後の成株で, 子株は切除し た。実験は 7 月 12 日より 27 日間, ビニールハウス内で行った。窒素形 態については, $\mathrm{NH}_{4}-\mathrm{N}$ のみ, $\mathrm{NH}_{4}-$ $\mathrm{N}$ と $\mathrm{NO}_{3}-\mathrm{N}$ の混合 $(5: 5)$ および $\mathrm{NO}_{3}-\mathrm{N}$ の の 3 処理区とし，その 各々について,さらに $\mathrm{pH}$ を 5,6 , $7 ， 8$ に調節した区を設けた。また， 総窒素濃度は $0,20,160 \mathrm{ppm} の 3$ 区を設定した。アンモニア態窒素と しては $\left(\mathrm{NH}_{4}\right)_{2} \mathrm{SO}_{4}$ を, 硝酸態空 素としては $\mathrm{NaNO}_{3}$ を使用し, 窒素 以外の要素については Table 1. に 準じ, ポリエチレン容器に $40 l$ の培

Tale 1. Composition of culture solution.

\begin{tabular}{l|r|lr}
\hline \multicolumn{1}{c|}{ Source } & $\begin{array}{l}\text { Concen- } \\
\text { tration }\end{array}$ & \multicolumn{2}{|c}{ Element } \\
\hline $\mathrm{Na}_{2} \mathrm{HPO}_{4} \cdot 12 \mathrm{H}_{2} \mathrm{O}$ & 63.1 & $\mathrm{P}_{2} \mathrm{O}_{5}$ & 12.5 \\
$\mathrm{mCl}$ & 39.9 & $\mathrm{~K}_{2} \mathrm{O}$ & 25.2 \\
$\mathrm{MgSO}_{4} \cdot 7 \mathrm{H}_{2} \mathrm{O}$ & 123.0 & $\mathrm{MgO}$ & 20.0 \\
$\mathrm{CaCl}_{2} \cdot 2 \mathrm{H}_{2} \mathrm{O}$ & 57.7 & $\mathrm{CaO}$ & 22.2 \\
EDTA-Na-Fe salt & 20.6 & $\mathrm{Fe}_{2} \mathrm{O}_{3}$ & 4.3 \\
\hline
\end{tabular}

養液を入れて一処理区とし，4 個体 を供試した。液の交換は，1週間 ごとに行い, $\mathrm{pH}$ は隔日に $1 / 10 \mathrm{~N}$ $\mathrm{NaOH}, 1 / 10 \mathrm{~N} \mathrm{HCl}$ で調節した。 適宜, 生育調査を行い, 実験終了後, 生体重と乾物重を測定し, 親株茎葉 部のみ分析試料とした。茎葉部内の $\mathrm{N}$ 含量はガンニング変法, $\mathrm{P}$ はバナ ドモリブデン酸アンモニウ:ム法, $\mathrm{K}, \mathrm{Ca}, \mathrm{Mg}$ 及び $\mathrm{Fe}$ は原子吸光分 光分析法により分析した。

\section{2. 実験結果及び考察}

\section{（1）生 育 状 況}

\section{i ) 各窒素形態区における $\mathrm{pH}$ の影響}

Fig. 1. 及び Fig. 2. に実験終了

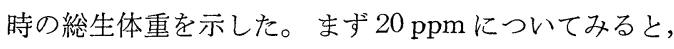
$\mathrm{NH}_{4}-\mathrm{N}$ 区では， $\mathrm{pH}$ が上昇するに伴い，生体重及び子 株形成数の増加が顕著に認められた。 $\mathrm{NH}_{4}-\mathrm{N}+\mathrm{NO}_{3}-\mathrm{N}$ 区は，中性からやや塩基性側で生育が良く，比較的広範 囲な $\mathrm{pH}$ でも生育良好であった。これに反して, $\mathrm{NO}_{3}-\mathrm{N}$

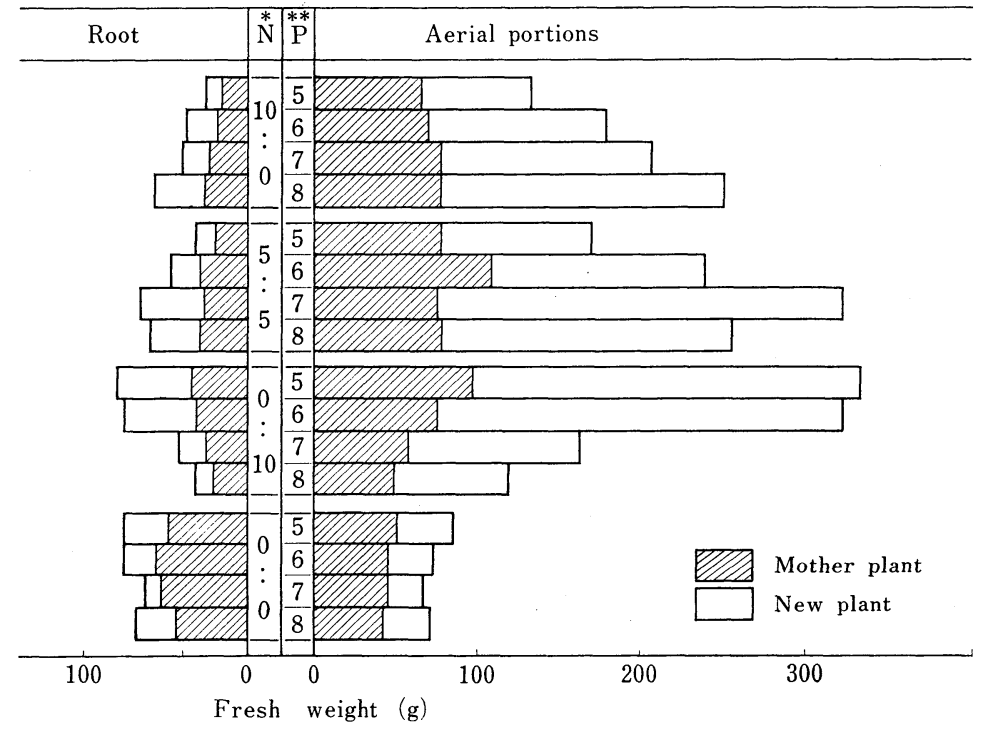

Fig. 1. $\mathrm{pH}$ effect on fresh weight in the $20 \mathrm{ppm}$ total $\mathrm{N}$ solution with different nitrogen forms.

Note: $* \mathrm{NH}_{4}-\mathrm{N} \quad * * \mathrm{pH}$ $\mathrm{NO}_{3}-\mathrm{N}$

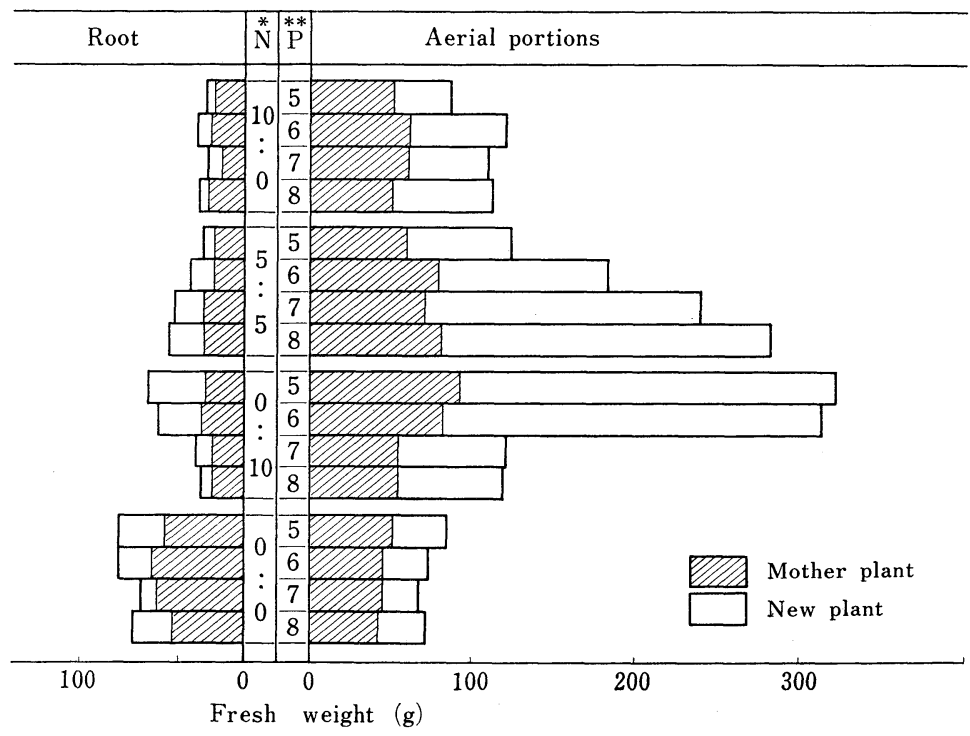

Fig. 2. $\mathrm{pH}$ effect on fresh weight in the $160 \mathrm{ppm}$ total $\mathrm{N}$ solution with different nitrogen forms.

$$
\begin{gathered}
\text { Note: } \\
* \mathrm{NH}_{4}-\mathrm{N} \\
\vdots \\
\mathrm{NO}_{3}-\mathrm{N}
\end{gathered}
$$


区は，pH5，6で生育が促進され，pH 7，8で抑制され た。奥田ら ${ }^{6)}$ は, 植物の窒素供給源として両形態のいず れが優れているかは，特に培養液の $\mathrm{pH}$ によることを強 調して扔り，また一般に，アンモニア態の場合は塩基性 側，硝酸態の場合は酸性側で良好な生育を示すといわれ ている ${ }^{3)}$ 。本実験に抒いても，上記と全く一致した結果 が得られた。一方, $160 \mathrm{ppm}$ では, $\mathrm{NO}_{3}-\mathrm{N}$ 区, $\mathrm{NH}_{4}-\mathrm{N}$ $+\mathrm{NO}_{3}-\mathrm{N}$ 区其 $20 \mathrm{ppm}$ と同様の傾向を示したが, $\mathrm{NH}_{4}-$ $\mathrm{N}$ 区のみは $\mathrm{pH}$ に関係なく葉質がかたく，褐色化した部 分が目立ち，著しく生育が抑制され， $0 \mathrm{ppm}$ と大差ない 生育量となった。また, 根部における障害む大きかった。 本実験の場合は，前報の窒素濃度の実験と比較して日最 高水温が $40^{\circ} \mathrm{C}$ を越える高温条件下で行ったため， $\mathrm{PEN}$ FOUND ら (1948) $)^{7)}$ が認めている高温障害を起こし，かつ 過剩窒素と相まって生育阻害をひき起こしたものと推察 される。次に $0 \mathrm{ppm}$ では， $\mathrm{pH}$ 間の差は認められず，一 様に生育が劣り，葉質は柔らかで葉色は黄色味を帯び,

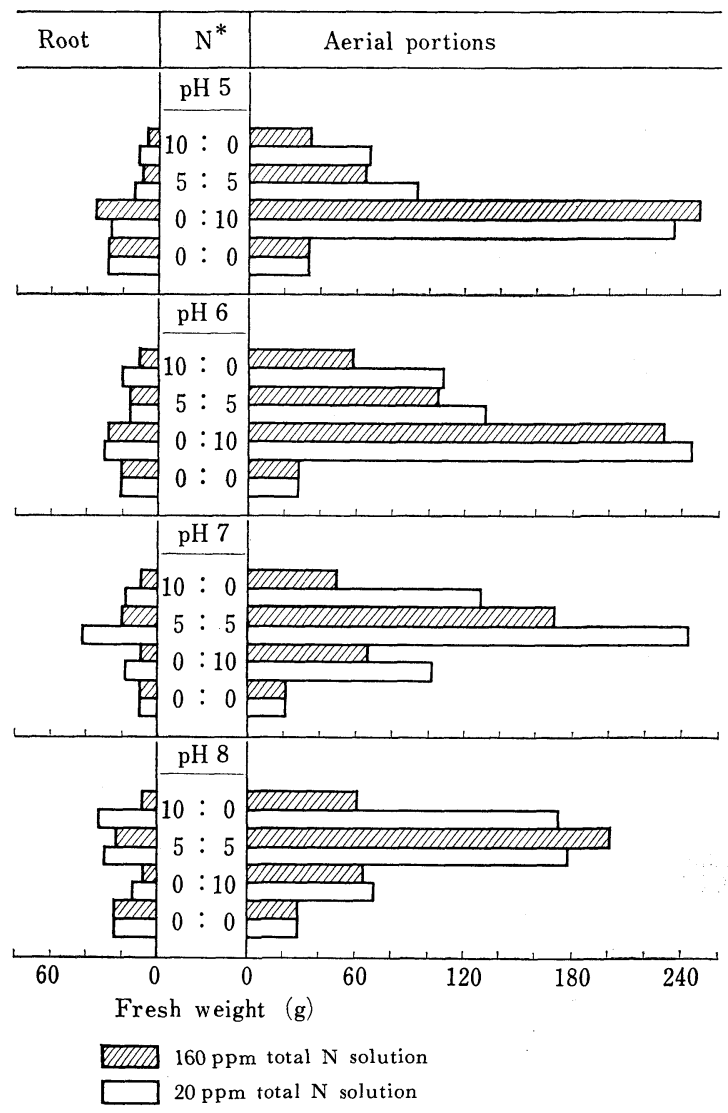

Fig. 3. Effect of nitrogen form on the growth of new plants in nutrient solution with different $\mathrm{pH}$ levels.

Note: $* \mathrm{NH}_{4}-\mathrm{N}: \mathrm{NO}_{3} \cdot \mathrm{N}$
茎葉部に対する根部の生育が大きく，青紫色を呈した。

ii ) $\mathrm{pH}$ が一定の場合に抢ける各窒素形態間の生育差 生育差は, 親株間ではほとんど認められなかったが, 新しく形成された子株数とその生育量に影響が現れたの で，これらの結果を Fig. 3. に示した。すなわち, $\mathrm{pH}$ 5,6 に掠いては $\mathrm{NO}_{3}-\mathrm{N}$ 区が他の 2 区上り著しく生育 良好であり， $\mathrm{pH} 7,8$ では $\mathrm{NH}_{4}-\mathrm{N}+\mathrm{NO}_{3}-\mathrm{N}$ 区が良 好であった。また， $\mathrm{pH} 8$ の $20 \mathrm{ppm}$ では $\mathrm{NH}_{4}-\mathrm{N}$ 区の 生育量が $\mathrm{NH}_{4}-\mathrm{N}+\mathrm{NO}_{3}-\mathrm{N}$ 区と同程度に達した。一方, 根部の生育をみると, 茥葉部の傾向と一致していること がわかった。本草の場合には，BENNETT ら (1964) 1) が トウモロコシで報告しているような， $\mathrm{NH}_{4}-\mathrm{N}$ 区が $\mathrm{NO}_{3}-\mathrm{N}$ 区に比べ根の発育が悪く，黒ずむ徵候は認めら れなかった。

ところで, $\mathrm{pH}$ 調整 2 日後の培養液の $\mathrm{pH}$ の変化を Fig. 4. に示したが，塩類吸収の結果， $\mathrm{NH}_{4}-\mathrm{N}$ 区では 酸性側に， $\mathrm{NO}_{3}-\mathrm{N}$ 区では塩基性側に傾いており，特に $\mathrm{NH}_{4}-\mathrm{N}+\mathrm{NO}_{3}-\mathrm{N}$ 区ではいずれの $\mathrm{pH}$ 区でも酸性側に 傾いていることが認められた。両窒素源を同一溶液に含 む場合，アンモニア態窒素と硝酸態窒素とが必ずしも均 等に吸収されるとは限らない。本実験の場合も, 混合区 が $\mathrm{NH}_{4}-\mathrm{N}$ 区と同じ傾向を示していることから，アンモ

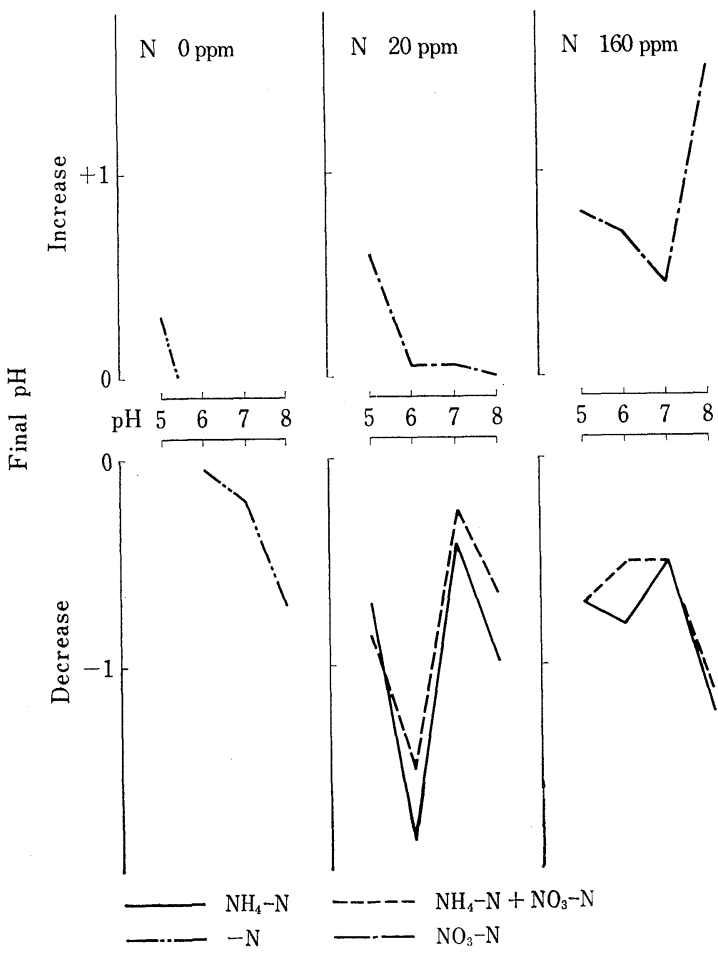

Fig. 4. Changes in $\mathrm{pH}$ of the nutrient solution after two days renewed the solution. 
Table 2. Mineral content of aerial portions of mother plant.

\begin{tabular}{|c|c|c|c|c|c|c|c|c|c|}
\hline \multicolumn{5}{|c|}{$\mathrm{N}$ content ( $\%$ on dry matter basis) } & \multicolumn{5}{|c|}{$\mathrm{Ca}$ content ( $\%$ on dry matter basis) } \\
\hline \multirow{2}{*}{$\mathrm{pH}$} & \multirow{2}{*}{$\begin{array}{l}\text { N level } \\
(\mathrm{ppm})\end{array}$} & \multicolumn{3}{|c|}{$\mathrm{N}$ form } & \multirow{2}{*}{$\mathrm{pH}$} & \multirow{2}{*}{$\begin{array}{l}\text { N level } \\
\text { (ppm) }\end{array}$} & \multicolumn{3}{|c|}{$\mathrm{N} \quad$ form } \\
\hline & & $\mathrm{NH}_{4}-\mathrm{N}$ & $\mathrm{NH}_{4}-\mathrm{N}+\mathrm{NO}_{3}-\mathrm{N}$ & $\mathrm{NO}_{3}-\mathrm{N}$ & & & $\mathrm{NH}_{4}-\mathrm{N}$ & $\mathrm{NH}_{4}-\mathrm{N}+\mathrm{NO}_{3}-\mathrm{N}$ & $\mathrm{NO}_{3}-\mathrm{N}$ \\
\hline 5 & $\begin{array}{r}0 \\
20 \\
160\end{array}$ & $\begin{array}{l}0.93 \\
4.13 \\
5.73\end{array}$ & $\begin{array}{l}\ldots \ldots \\
5.48 \\
6.78\end{array}$ & $\begin{array}{l}\ldots \ldots \\
3.58 \\
5.43\end{array}$ & 5 & $\begin{array}{r}0 \\
20 \\
160\end{array}$ & $\begin{array}{l}2.20 \\
1.30 \\
1.16\end{array}$ & $\begin{array}{l}\ldots \ldots \\
1.40 \\
1.03\end{array}$ & $\begin{array}{l}\ldots \ldots \\
1.93 \\
1.56\end{array}$ \\
\hline 6 & $\begin{array}{r}0 \\
20 \\
160\end{array}$ & $\begin{array}{l}0.90 \\
5.13 \\
6.58\end{array}$ & $\begin{array}{l}\ldots \ldots \\
5.45 \\
6.15\end{array}$ & $\begin{array}{l}\ldots . . \\
3.10 \\
4.95\end{array}$ & 6 & $\begin{array}{r}0 \\
20 \\
160\end{array}$ & $\begin{array}{l}2.50 \\
1.06 \\
1.13\end{array}$ & $\begin{array}{l}\ldots \ldots \\
1.56 \\
1.20\end{array}$ & $\begin{array}{l}\ldots \ldots \\
2.03 \\
1.96\end{array}$ \\
\hline 7 & $\begin{array}{r}0 \\
20 \\
160\end{array}$ & $\begin{array}{l}1.25 \\
5.33 \\
6.85\end{array}$ & $\begin{array}{l}\ldots \ldots \\
4.28 \\
5.03\end{array}$ & $\begin{array}{l}\ldots \ldots \\
4.13 \\
4.60\end{array}$ & 7 & $\begin{array}{r}0 \\
20 \\
160\end{array}$ & $\begin{array}{l}2.40 \\
1.46 \\
1.06\end{array}$ & $\begin{array}{l}\ldots \ldots \\
1.73 \\
1.46\end{array}$ & $\begin{array}{l}\ldots \ldots \\
2.06 \\
2.00\end{array}$ \\
\hline 8 & $\begin{array}{r}0 \\
20 \\
160\end{array}$ & $\begin{array}{l}0.98 \\
4.83 \\
8.08\end{array}$ & $\begin{array}{l}\ldots \ldots \\
3.78 \\
5.63\end{array}$ & $\begin{array}{l}\ldots \ldots \\
4.15 \\
4.58\end{array}$ & 8 & $\begin{array}{r}0 \\
20 \\
160\end{array}$ & $\begin{array}{l}2.60 \\
1.63 \\
1.10\end{array}$ & $\begin{array}{l}\ldots \ldots \\
1.96 \\
1.30\end{array}$ & $\begin{array}{l}\ldots \ldots \\
1.83 \\
2.40\end{array}$ \\
\hline \multicolumn{5}{|c|}{$\mathrm{P}$ content ( $\%$ on dry matter basis) } & \multicolumn{5}{|c|}{$\mathrm{Mg}$ content ( $\%$ on dry matter basis) } \\
\hline 5 & $\begin{array}{r}0 \\
20 \\
160\end{array}$ & $\begin{array}{l}0.44 \\
0.64 \\
1.14\end{array}$ & $\begin{array}{l}\ldots \ldots \\
0.77 \\
0.83\end{array}$ & $\begin{array}{l}\ldots \ldots \\
0.39 \\
0.45\end{array}$ & 5 & $\begin{array}{r}0 \\
20 \\
160\end{array}$ & $\begin{array}{l}1.23 \\
0.57 \\
0.60\end{array}$ & $\begin{array}{l}\ldots \ldots \\
0.83 \\
0.77\end{array}$ & $\begin{array}{l}\ldots \ldots \\
1.20 \\
1.00\end{array}$ \\
\hline 6 & $\begin{array}{r}0 \\
20 \\
160\end{array}$ & $\begin{array}{l}0.48 \\
0.62 \\
1.03\end{array}$ & $\begin{array}{l}\ldots .7 \\
0.74 \\
0.80\end{array}$ & $\begin{array}{l}\ldots \ldots \\
0.49 \\
0.56\end{array}$ & 6 & $\begin{array}{r}0 \\
20 \\
160\end{array}$ & $\begin{array}{l}1.53 \\
0.57 \\
0.87\end{array}$ & $\begin{array}{l}\ldots \ldots \\
0.87 \\
0.70\end{array}$ & $\begin{array}{l}\ldots \ldots \\
1.30 \\
1.00\end{array}$ \\
\hline 7 & $\begin{array}{r}0 \\
20 \\
160\end{array}$ & $\begin{array}{l}0.49 \\
0.68 \\
0.91\end{array}$ & $\begin{array}{l}\ldots . . \\
0.53 \\
0.83\end{array}$ & $\begin{array}{l}\ldots . . \\
0.55 \\
0.61\end{array}$ & 7 & $\begin{array}{r}0 \\
20 \\
160\end{array}$ & $\begin{array}{l}1.50 \\
0.70 \\
0.73\end{array}$ & $\begin{array}{l}\ldots \ldots \\
1.13 \\
0.90\end{array}$ & $\begin{array}{l}\ldots \ldots \\
1.07 \\
1.13\end{array}$ \\
\hline 8 & $\begin{array}{r}0 \\
20 \\
160\end{array}$ & $\begin{array}{l}1.50 \\
1.03 \\
0.90\end{array}$ & $\begin{array}{l}\ldots \ldots \\
1.20 \\
0.90\end{array}$ & $\begin{array}{l}\ldots \ldots \\
1.03 \\
1.07\end{array}$ & 8 & $\begin{array}{r}0 \\
20 \\
160\end{array}$ & $\begin{array}{l}0.49 \\
0.91 \\
1.02\end{array}$ & $\begin{array}{l}\ldots \ldots \\
0.62 \\
0.63\end{array}$ & $\begin{array}{l}\ldots \ldots \\
0.40 \\
0.44\end{array}$ \\
\hline \multicolumn{5}{|c|}{$\mathrm{Fe}$ content ( $\%$ on dry matter basis) } & \multicolumn{5}{|c|}{$\mathrm{K}$ content ( $\%$ on dry matter basis) } \\
\hline 5 & $\begin{array}{r}0 \\
20 \\
160\end{array}$ & $\begin{array}{l}0.078 \\
0.111 \\
0.172\end{array}$ & $\begin{array}{l}\ldots \ldots . \\
0.141 \\
0.093\end{array}$ & $\begin{array}{l}\ldots \ldots \\
0.064 \\
0.068\end{array}$ & 5 & $\begin{array}{r}0 \\
20 \\
160\end{array}$ & $\begin{array}{l}5.16 \\
4.83 \\
4.50\end{array}$ & $\begin{array}{l}\ldots \ldots . . \\
6.16 \\
3.03\end{array}$ & $\begin{array}{l}\ldots \ldots \\
4.80 \\
3.43\end{array}$ \\
\hline 6 & $\begin{array}{r}0 \\
20 \\
160\end{array}$ & $\begin{array}{l}0.069 \\
0.114 \\
0.090\end{array}$ & $\begin{array}{l}\ldots \ldots \\
0.146 \\
0.087\end{array}$ & $\begin{array}{l}\ldots \ldots \\
0.075 \\
0.088\end{array}$ & 6 & $\begin{array}{r}0 \\
20 \\
160\end{array}$ & $\begin{array}{l}4.73 \\
5.20 \\
4.26\end{array}$ & $\begin{array}{l}\ldots \ldots \\
6.20 \\
3.06\end{array}$ & $\begin{array}{l}\ldots \ldots \\
4.43 \\
4.20\end{array}$ \\
\hline 7 & $\begin{array}{r}0 \\
20 \\
160\end{array}$ & $\begin{array}{l}0.069 \\
0.105 \\
0.076\end{array}$ & $\begin{array}{l}\ldots \ldots . \\
0.042 \\
0.074\end{array}$ & $\begin{array}{l}\ldots \ldots \\
0.081 \\
0.057\end{array}$ & 7 & $\begin{array}{r}0 \\
20 \\
160\end{array}$ & $\begin{array}{l}4.70 \\
6.30 \\
3.76\end{array}$ & $\begin{array}{l}\ldots \ldots \\
4.50 \\
3.10\end{array}$ & $\begin{array}{l}\ldots \ldots \\
7.13 \\
5.36\end{array}$ \\
\hline 8 & $\begin{array}{r}0 \\
20 \\
160\end{array}$ & $\begin{array}{l}0.058 \\
0.067 \\
0.066\end{array}$ & $\begin{array}{l}\ldots \ldots . \\
0.068 \\
0.065\end{array}$ & $\begin{array}{l}\ldots \ldots . \\
0.050 \\
0.093\end{array}$ & 8 & $\begin{array}{r}0 \\
20 \\
160\end{array}$ & $\begin{array}{l}4.36 \\
7.03 \\
3.66\end{array}$ & $\begin{array}{l}\ldots \ldots \\
5.36 \\
3.06\end{array}$ & $\begin{array}{l}\ldots \ldots \\
6.20 \\
4.33\end{array}$ \\
\hline
\end{tabular}

ニア態窒素が硝酸態窒素より選択的に吸収されていると 推察される。

\section{（2）茎葉部の無機成分含量}

親株茎葉部の各無機成分含有率を Table 2. 亿示した。 $0 \mathrm{ppm}$ と比較して, 窒素を与えることにより増加した成 分は窒素と燐で, 減少した成分はカルシウムとマグネ シウムであった。カリウムについては， 20 ppm で増加, 160 ppm で減少の傾向が認められた。

一方, 個々の成分について検討すると, 各形態間およ び $\mathrm{pH}$ により差が生じた。窒素含有率は， $\mathrm{NO}_{3}-\mathrm{N}$ 区に 比べ $\mathrm{NH}_{4}-\mathrm{N}$ 区が常に高く, その傾向は $\mathrm{pH}$ が高くなる ほど, また窒素濃度が高いほど顕著であった。特に, 生 育に障害が認められた $160 \mathrm{ppm} \mathrm{NH}_{4}-\mathrm{N}$ 区においては, $\mathrm{pH}$ の上昇に伴い窒素含有率は著しく増加した。 $\mathrm{NH}_{4}-\mathrm{N}$ 区の方が窒素含有率が高いといら結果は, トマト, タバ コ，その他多くの野菜で認められているが，本草のよう に体内で高い含有率を示しているものは, どのような形 態で蓄積されているのか, 今後検討を要する。同じ増加
の傾向を示す燐に関しても， $\mathrm{NH}_{4}-\mathrm{N}$ 区の含有率が高 い。おそらく $\mathrm{NO}_{3}$ イオンと $\mathrm{P}$ イオンとの間に陰イオン 間の拮抗が生じたためか, あるいは $\mathrm{NH}_{4}-\mathrm{N}$ 区の根の吸 収面の $\mathrm{pH}$ が低く, 燐を有効状態に保っていることが関 倸しているのではないかと考えられる。また，いずれの 区も含有率は $\mathrm{pH}$ に影響されず, 一般に他の野菜類と比 較して，やや高い值を示している。

次に，カリウム含有率は， $\mathrm{pH}$ および窒素濃度による 各形態間の差が大きい。一般にカリウムは条件により変 化を受けやすいとされているが, $\mathrm{NaNO}_{3}$ を使用した場 合, Naイオンが拮抗的に働き, カリウム含有率に影響 を与えるといわれる ${ }^{3)}$ 。一方, 無窒素区と比べ減少の傾 向を示すカルシウム，マグネシウムに関しては，いずれ の $\mathrm{pH}$ 区でも $\mathrm{NO}_{3}-\mathrm{N}$ 区が $\mathrm{NH}_{4}-\mathrm{N}$ 区より顕著に高い含 有率を示している。このことは, 吸収に扔いて $\mathrm{NH}_{4}$ イ オンと $\mathrm{Ca}$ 及び $\mathrm{Mg}$ イオンとの間に強い捛抗作用があ るためと考えられる。さらに, $20 \mathrm{ppm} \mathrm{NH}_{4}-\mathrm{N}$ 区は両 成分共 $\mathrm{pH}$ 上昇に伴い含有率が高くなって拉り, 生育量 
増加の傾向と一致していることから，両成分は窒素の正 常な同化に好影響を及ぼしてると考えられる。カル シウムは, 窒素濃度による含有率の変動の幅が他の成分 と比較して大きいが，EASLEY ら (1974) ${ }^{2)}$ が水生植 物のカルシウム含有量は陸生植物より高いと指摘する通 り，本草のカルシウム含有率は高かった。総じて，各窒 素間および $\mathrm{pH}$ 間で無機成分含有率の增減が大きく影響 されたのは $\mathrm{NH}_{4}-\mathrm{N}$ 区であった。

一般に，比較的新しい污染水域ではアンモニア態窒素 が多く，古くなるにつれて硝酸態窒素が増加する傾向が ある。著者らが，本草繁茂地の水質調査を行った結果，

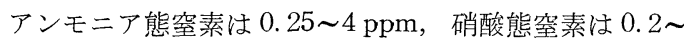
$0.4 \mathrm{ppm}$ の範囲で， $\mathrm{pH}$ は 6.6〜7.2であった ${ }^{9)}$ 。本実験 は，高濃度で行ったが，窒素両形態と $\mathrm{pH}$.に対する本草 の反応を把握したことは，今後，繁茂が懸念される水域 の一指標になると考えられる。現在，本草の防除手段は 種々試みられているが，いずれの場合も，本草の生育な らびに繁殖特性に関する基礎資料を踏まえて検討を加え なければならない。従って, 早急にこの種の基礎研究を 固める必要性を痛感する。

\section{3. 摘 要}

水中の窒素形態の差異がホテイアオイの生育ならびに繁 殖に及ぼす影響を，種々の $\mathrm{pH}$ 条件下で調べた。

（1）各窒素形態区に捻ける $\mathrm{pH}$ の影響を調べた結 果, $\mathrm{NH}_{4}-\mathrm{N}$ 区および $\mathrm{NH}_{4}-\mathrm{N}+\mathrm{NO}_{3}-\mathrm{N}$ 区は中性から 塩基性側で，一方， $\mathrm{NO}_{3}-\mathrm{N}$ 区は酸性側で，生育や繁殖 が促進された。
（2） $\mathrm{pH}$ が一定の場合の各窒素形態間の生育差を, 新しく形成された子株の生育量で調べると，pH5，6で $\mathrm{NO}_{3}-\mathrm{N}$ 区が著しく生育良好で， $\mathrm{pH} 7,8$ で $\mathrm{NH}_{4}-\mathrm{N}+$ $\mathrm{NO}_{3}-\mathrm{N}$ 区が良好であった。

（3）調整後の培養液の $\mathrm{pH}$ 変化から，アンモニア態 窒素が硝酸態窒素より選択的に吸収されていることが推 察された。

（4）親株茎葉部の無機成分含有率を測定すると, $\mathrm{pH}$ に関係なく，窒素含量と燐含量は $\mathrm{NO}_{3}-\mathrm{N}$ 区より $\mathrm{NH}_{4}-\mathrm{N}$ 区で高く， カルシウム含量はその逆の傾向を示 した。

\section{引用 文 献}

1) Bennett, W.F., J. Pesek and R. D. Blackburn: Effect of Nitrate and Ammonium on Growth of Corn in Nutrient Solution Sand Culture. Agronomy Journal 56, 342 345 (1964).

2) Easley, J. F. and R. L. Shirley : Nutrient elements for livestock in aquatic plants. Hyacinth Control Journal 12 (May), 82 85 (1974).

3）岩田正利：窒素形態の差異と蔬菜の生育（第 3 報）、園芸学会雑誌 31 (1), 39〜52 (1962).

4）大垣健吉：ホテイアオイのメカニズムと，その特性に関する研究報 告書, 19 (1974).

5）沖陽子・伊藤操子・植木邦和：ホティアオイ（Eichhornia crassipes (Mart.) Solms) の生育及び繁殖に関する研究. 雑草 研究 23 (3), 15 20 (1978).

6) 奥田 東・下瀬 昇: 作物の窒素代謝に関する研究. 日土肥雑 22 (2), 6 8 (1951).

7) Penfound WM. T. and T. T. EarLe: The Biology of the Water Hyacinth. Ecological Monographs 18 (4), 447 472 (1948).

8）高橋英一：「作物栄養学」第IV章, 朝倉書店, (1972).

9) UEKI, K., M. ITO and Y. OKI: Waterhyacinth and Its Habitats in Japan. Proceedings of the fifth Asian-Pacific Weed Science Society Conference, Tokyo, 424 428 (1976).

(1978 年 5 月 8 日受理)

\title{
Studies on the Growth and Reproduction of Waterhyacinth,
} Eichhornia crassipes (Mart.) Solms

2. Effect of Nitrogen Sources on the Growth and Reproduction

\author{
Yoko OkI, Misako Ito, and Kunikazu UeKI
}

Faculty of Agriculture, Kyoto University, Kyoto 606

\section{Summary}

An experiment was designed to study the influence of the sources of nitrogen supplied on the growth. The sources of nitrogen were ammonium $\left(\mathrm{NH}_{4}-\mathrm{N}\right)$, nitrate $\left(\mathrm{NO}_{3}-\mathrm{N}\right)$ and the two $\left(\mathrm{NH}_{4}-\mathrm{N}\right.$ $\left.+\mathrm{NO}_{3}-\mathrm{N}\right)$.

1) Maximum growth of both $\mathrm{NH}_{4}-\mathrm{N}$ and $\mathrm{NH}_{4}-\mathrm{N}+\mathrm{NO}_{3}-\mathrm{N}$ plants occured in neutral or slightly basic water, while the growth of $\mathrm{NO}_{3}-\mathrm{N}$ plants were greater in acidic water than those in neutral or 
slightly basic water.

2) The new plants grew well in the $\mathrm{NO}_{3}-\mathrm{N}$ at $\mathrm{pH} 5$ and $\mathrm{pH} 6$, but they reached maximum growth in the $\mathrm{NH}_{4}-\mathrm{N}+\mathrm{NO}_{3}-\mathrm{N}$ at $\mathrm{pH} 7$ and $\mathrm{pH} 8$.

3) Measurements of the initial and final $\mathrm{pH}$ levels of the culture waters indicated that ammonium was absorbed more selectively than nitrate by the plants in the nutrient with $\mathrm{NH}_{4}-\mathrm{N}+\mathrm{NO}_{3}-\mathrm{N}$.

4) Both total nitrogen content and total phosphorus content of the $\mathrm{NH}_{4}-\mathrm{N}$ plants were higher than those of the plants in $\mathrm{NO}_{3}-\mathrm{N}$, while the calcium content of $\mathrm{NH}_{4}-\mathrm{N}$ plants was low.

\title{
生育初期におけるイネとノビエの生理的特性の比較*
}

\author{
京都大学農学部 一前宣 正 ${ }^{* *} \cdot$ 植木邦和
}

イネとノビエの間に選択殺草性を示す除草剤として は, プロパニル (3,4-dichloropropionanilide $)^{10)}$, ベン チオカーブ $[S$-(4-chlorobenzyl)- $N, N$-diethylthiolcarbamate $]^{12)}$, モリネート ( $S$-ethyl-hexahydro-1Hazepin-1-carbothioate) などが知られているが, プロパ ニルを除く他の除草剤では選択殺草性の機構が十分に解 明されていないように考えられる。

一般に除草剤氾対する植物の感受性の差異は, 薬剤の 吸収量, 移行量, 代謝能力の差異によって生じるもの で, その起因は対象とする植物の形態的, 生理的, 生態 的, 生化学的な特性に求めることができる ${ }^{19}$ 。

もとよりイネは人類の食糧源として極めて重要な作物 で, これに関する研究は膨大である。一方, ノビエは古 くからイネの強害草として知られている。しかしなが ら, 現在までにイネとノビエの特性を比較した文献は 比較的少なく, 種子の大きさ ${ }^{5)}$, 発芽々初期生育の様 相 $^{1,3,13)}$, 葉部組織 ${ }^{2,7,14,18)}$ ならびに根系 ${ }^{2)}$ などに差異の あることが報告されているにすぎない。

本報は, 以上の観点から, 生育初期のイネとノビエに 扔いて除草剂に対する感受性の差異に関与すると考えら れる 2,3 の生理的特性を比較したものである。

\section{1. 実験材料ならびに方法}

供試植物は，1976 年宇都宮で採種したタイヌビエと ケイヌビエ，イネとして金南風と日本晴 (Japonica 型) ならびに台中在来 1 号と統一 (Indica 型) である。

植物の育成は, 温度 $28^{\circ} \mathrm{C}$, 照度 10,000 ルックスの条 件下で行った。供試植物は，西らかじめ16メッシュの
ふるい（節）を通した白川砂を入れた植物育成器に播種 し，1葉期に根を痛めないように抜き取った。その後 は, 木村氏 $\mathrm{B}$ 水耕液を入れたバットに $2 \mathrm{~cm}$ 間隔で直径 $1 \mathrm{~cm}$ の穴をあけた発泡スチロールの薄板を浮かべ, こ の穴に根部を通して葉䩗基部をウレタンで固定の後，4 葉期まで生育させた。

乾物重量と水分含量は 1 葉期から 4 葉期の各植物につ いて測定した。重量測定は 10 個体ごとに行い, 5 連制と した。水分含量は $\{$ (生体重一乾重物 $) /$ 生体重 $\times 100\}$ 加 ら算出した。

気孔数と葉緑素含量は 2 葉期の各植物について測定し た。実験は, 第 1 本葉葉䩗と第 2 本葉葉身のスンプ標 本 ${ }^{15)}$ を作成し, 葉面積 $0.64 \mathrm{~mm}^{2}$ 当たりの気孔数を測定 した。葉緑素含量は, 各植物の茥葉部をガラスホモジナ イザーに入れ，80％アセトンを加えて葉緑素を抽出し， 645, $663 \mathrm{~nm}$ の吸光度で測定し, 計算式から求めた ${ }^{9}$ 。 実験は 5 連制とした。

蒸散量は常法 ${ }^{16)}$ に準拠して測定した。供試植物は 1 葉 期から 4 葉期までの植物で, 葉䩗基部をゴム栓で固定 し, 蒸留水を入れた三角フラスコに立て, 温度 $28^{\circ} \mathrm{C}$, 照 度 10,000 ルックスの条件下に置いた。その後は, 1 時間 ごとに 5 回にわたってフラスコの重量を測定し, 測定前 後の重量差から蒸散量を求めた。実験は 5 連制とした。

根の浸透圧, 呼吸, TTC 還元力は 2 葉期の植物につ いて測定した。浸透圧は, 直径 $0.02 \sim 0.03 \mathrm{~mm}$ の毛細 根を $20^{\circ} \mathrm{C}$ で 40 分間所定の $\mathrm{NaCl}$ 溶液に浸漬の後, 原形 質分離の有無を検鏡し, 初発原形質分離の濃度加算出 した。呼吸量は種子根の切片における酸素吸収量を酸素

* 大要は日本雑草学会第 17 回講演会（1978 年 4 月）に扣いて発表した。

** 京都大学研修員。現在, 宇都宮大学農学部雑草防除研究施設 